\title{
CUIDADOS PALIATIVOS: percepção de cuidadores familiares de idosos em tratamento oncológico
}

\author{
PALLIATIVE CARE: \\ perception of caregivers of the \\ elderly in cancer treatment
}

\section{Denize Alves de Almeida', Sandramar de Lima Silveira², Wallisete de Almeida Godinho Rosa Mariana Gondim Mariutti Zeferino ${ }^{3}$, Nariman de Felicio Bortucan Lenza ${ }^{3}$}

\begin{abstract}
RESUMO
Investigar a percepção acerca de cuidados paliativos de cuidadores familiares de idosos em tratamento oncológico cadastrados em uma Associação de Combate ao Câncer. Metodologia: Pesquisa de campo, descritiva, do tipo transversal, de abordagem qualitativa, por meio de entrevistas semiestruturadas, que foram transcritas e categorizadas. Resultados: foram identificadas seis categorias que demonstram que os cuidadores apesar de não terem muito conhecimento acerca de cuidados paliativos, os praticam em dimensões variadas, seja oferecendo uma alimentação saudável, realizando higiene adequada, buscando 0 alívio da dor e mantendo atenção e cuidado quanto a medicação prescrita. Alguns referem que se sentem desamparados e sobrecarregados ao oferecer os cuidados necessários ao familiar com câncer, além de enfrentar limitações físicas. A enfermagem tem papel fundamental nos cuidados paliativos e na atenção aos cuidadores, no sentido de traçar estratégias de ensino e capacitação desses para que possam aprimorar 0 ato de cuidar e se sintam mais amparados.
\end{abstract}

Descritores: Cuidados Paliativos; Neoplasias; Idoso.

\section{ABSTRACT}

To investigate the perception about palliative care of family caregivers of elderly people on cancer treatment enrolled in a Cancer Combat Association. Methodology: Field research, descriptive, crosssectional, qualitative approach, through semi-structured interviews, which were transcribed and categorized. Results: six categories were identified that demonstrate that caregivers, although not very knowledgeable about palliative care, practice them in a variety of dimensions, either by providing a healthy diet, by performing adequate hygiene, by seeking pain relief, and by maintaining attention and care for Medication. Some report that they feel helpless and overwhelmed by offering the necessary care to the family member with cancer, in addition to facing physical limitations. Nursing plays a pivotal role in palliative care and attention to caregivers, in the sense of designing teaching strategies and enabling them to improve caregiving and feel more protected.
${ }^{1}$ Mestre pela Escola de Enfermagem de Ribeirão Preto (EERP/USP), Ribeirão Preto, SP, Brasil.

${ }^{2}$ Graduada em Enfermagem pela Libertas Faculdades Integradas, São Sebastião do Paraíso, MG, Brasil.

${ }^{3}$ Doutora em Enfermagem pela Escola de Enfermagem de Ribeirão Preto (EER/USP), Ribeirão Preto, SP, Brasil. 


\section{Introdução}

Segundo a Organização Mundial da Saúde (OMS) os Cuidados Paliativos (CP) objetivam a melhoria da qualidade de vida do paciente e seus familiares, através da prevenção e alívio do sofrimento, da identificação precoce, avaliação impecável e tratamento de dor e demais sintomas físicos, sociais, psicológicos e espirituais ${ }^{1-3}$.

A enfermagem juntamente com a equipe multidisciplinar realiza cuidados humanizados para ajudar doentes e familiares a se adaptarem às novas mudanças de vida geradas pela doença oncológica, podendo promover alívio da dor, de outros sintomas e respostas fisiológicas do paciente em cuidados paliativos ${ }^{4}$.

As neoplasias malignas atualmente são consideradas um importante problema de saúde pública ${ }^{1,3} .0$ Instituto Nacional do Câncer (INCA) estima nos anos de 2016 e 2017 que haverá cerca de 600 mil casos novos de câncer no Brasil, sendo 420 mil de todos os tipos, com exceção do câncer de pele não melanoma. A OMS estima para 0 ano de 2030, 27 milhões de novos casos, 17 milhões de mortes e 75 milhões de pessoas vivas com câncer nos países em desenvolvimento como o Brasil ${ }^{1,3,5}$.

Atualmente, os avanços científicos e tecnológicos na área da saúde aumentaram as chances de tratamentos, índices de cura e sobrevivência a muitas doenças, inclusive as neoplasias malignas, o que fortalece a maior necessidade da utilização dos serviços de saúde e de cuidados paliativos a fim de atender às necessidades dessa população $0^{6-7}$.

A pessoa com neoplasia em estágio avançado apresenta diversos sintomas tais como caquexia, fadiga, dispnéia, náuseas, vômitos, dor, entre outros, que trazem muito sofrimento ao paciente e sua família, além da incapacidade e prejuízos à qualidade de vida. Assim, para que os cuidados sejam prestados de forma adequada é importante saber avaliar e controlar os sintomas apresentados pelo doente, o que permitirá uma estratégia terapêutica mais eficaz, aliviando a dor e melhorando os sintomas e a qualidade de vida 8 .

A evolução do tratamento oncológico traz consigo o estigma do sofrimento, da dor, angústia, indignação e receio frente ao futuro incerto e à morte ${ }^{8}$. Assim, o medo se faz presente, o que causa maior sofrimento, fazendo-se necessário 0 acolhimento da pessoa doente para ajudá-lo no enfrentamento em relação à própria morte 8 .

A população idosa com neoplasia constitui um grupo diferenciado no que se refere aos cuidados necessários à sua saúde e bem-estar, já que conforme o tipo de tumor, das manifestações e do tratamento que for submetido, o idoso se torna mais suscetível às necessidades e limitações impostas pela doença ${ }^{6,9}$.

É de fundamental importância a maior aproximação com o idoso, conhecendo-o melhor, para identificar os cuidados que atendam às suas necessidades, a fim de individualizar a assistência. Nessa perspectiva, os cuidados paliativos, muitas vezes, são prestados por cuidadores, que em sua maioria, são familiares e por uma equipe multidisciplinar6,9-10.

A própria família é quem determina quem exercerá o papel específico de cuidador familiar, influenciado por fatores como gênero, idade, tempo disponível, afetividade, personalidade, grau de parentesco, situação financeira e local de residência ${ }^{10}$.

Uma vez que o cuidador familiar tem o compromisso de oferecer cuidados no domicílio, faz-se necessário que este familiar conheça os tipos de cuidados prestados por ele para que os profissionais de saúde possam orientá-lo, de forma que o cuidador consiga oferecer cuidados paliativos de qualidade ao idoso com câncer ${ }^{10,11}$. Assim, é importante conhecer o perfil do cuidador familiar sob os vários aspectos, de forma que se possa conhecer os cuidados que ele oferece no domicílio, para que ele receba o suporte necessário pela equipe de enfermagem.

Objetivou-se nesse estudo investigar a percepção dos cuidadores familiares de idosos em tratamento oncológico cadastrados na Associação de Combate ao Câncer (ACCa) acerca dos cuidados paliativos necessários para que 0 enfermeiro tenha subsídios necessários para levar ao cuidador informações pertinentes aos cuidados com o idoso em tratamento oncológico em suas várias dimensões, para minimizar o sofrimento e oferecer apoio psicológico a esse paciente e ao seu cuidador familiar.

\section{Metodologia}

Após aprovação pelo Comitê de Ética em Pesquisa da Fundação de Ensino Superior de Passos - FESP/MG, CAAE 24707513.6.0000.5112 em 08/12/2014, iniciou-se a pesquisa seguindo padrões éticos contidos na resolução número 466 de 2012 do Conselho Nacional de Saúde, que regulamenta pesquisas envolvendo seres humanos ${ }^{12}$.

A pesquisa foi realizada na Associação de Combate ao Câncer (ACCa), na cidade de São Sebastião do Paraíso $M G$, no período de janeiro a fevereiro de 2014. Foi feita pesquisa de campo, descritiva, do tipo transversal, de abordagem 
qualitativa, com entrevista semi-estruturada contendo as perguntas norteadoras: "Conte-me como você cuida da pessoa com câncer"; "Você tem alguma dificuldade para cuidar?"; "Você recebe suporte para desenvolver o cuidado?"; "Você acredita que o idoso vai se curar?"; "Conte-me o que você faz para que a pessoa se sinta bem".

Também foi feita uma pesquisa nos prontuários dos pacientes, que ficam arquivados na associação, para levantamento do perfil socioeconômico e cultural dos mesmos.

Os critérios de inclusão foram: ser cuidador familiar de idoso em tratamento oncológico em cuidados paliativos cadastrado na ACCa; cuidador maior de 18 anos; residir na área urbana e concordar em participar da pesquisa, assinando o termo de Consentimento Livre e Esclarecido.

Foram entrevistados 10 cuidadores familiares de pessoas em cuidados paliativos, de acordo com os critérios de inclusão da pesquisa. As entrevistas foram gravadas, em seguida transcritas e pré-analisadas através de leituras exaustivas; em seguida foi feita exploração do material para categorização de expressões ou palavras significativas (análise de conteúdo do tipo temática) e na sequência realizou-se um tratamento e interpretação dos resultados obtidos ${ }^{13,14}$.

Os entrevistados tiveram a sua identidade preservada através da letra "E" de entrevistado, acompanhado de um número que corresponde às visitas realizadas para se obter a entrevista.

Ao fazer a transcrição das respostas obtidas os autores se depararam com fragilidades linguísticas, justificadas pelo baixo nível cultural, o que fez com que fosse feita a opção pela transcrição exata do vocabulário utilizado pelos entrevistados. Também, ao considerar o baixo nível cultural, os pesquisadores, baseados na experiência dos profissionais da ACCa acharam por bem não perguntar se o cuidador familiar sabia o significado do termo "Cuidados Paliativos" evitando assim, constrangimentos. Sendo assim, nas entrevistas, os pesquisadores optaram por dar ênfase aos cuidados realizados e não ao significado literário da palavra.

\section{Resultados e Discussão}

Dos 10 participantes, oito eram do sexo feminino (80\%) e dois do sexo masculino (20\%). Quanto à idade um (1) cuidador tinha 22 anos (10\%), cinco tinham idade de 47 a 57 anos (50\%) e quatro de 66 a 72 anos (40\%).

Em relação à escolaridade em anos de estudo variou de zero a oito, sendo que a maioria (seis participantes) tinham quatro anos de estudo (60\%). Quanto à profissão, todos relataram ser apenas cuidadores e não ter outro serviço, com exceção de uma cuidadora que também era estudante.

Quanto ao grau de parentesco com o idoso dois eram filhos (20\%), seis esposos (as) (60\%), uma enteada (10\%) e uma irmã (10\%).

Em relação ao tempo que cuidavam dessas pessoas, oito relataram que cuidavam há mais de um ano (80\%), e dois há menos de um ano $(20 \%)$.

A renda familiar variou entre um (1) a três salários mínimos, sendo que quatro famílias recebiam um (1) salário $(40 \%)$, três recebiam dois salários $(30 \%)$, uma família recebia três salários $(10 \%)$ e duas com um pouco mais de um salário $(20 \%)$.

Os cuidadores em geral apresentam baixo nível socioeconômico e cultural e não tem bem definido o que são cuidados paliativos, mas em seu dia a dia os praticam em dimensões variadas, dependendo da realidade de cada um, sendo assim, da análise de conteúdo emergiram seis categorias, a saber: Cuidados desenvolvidos; Dificuldades sentidas pelo cuidador; Suporte para a realização do cuidado; Cura; Morte e Ações para a promoção do bem-estar.

\section{Cuidados desenvolvidos}

Os cuidadores focam nas entrevistas a importância da alimentação saudável dos idosos, seguindo os horários corretos e buscando oferecer alimentos que o idoso tem preferência:

"[... de manhã eu já faço, eu bato lá os alimento dele, depois de novo lá pelas nove e meia, de novo tem alimentação, aí eu faço suco de fruta, trago pra ele, tenho que tê o tempo de pô água, pa limpá, depois de vinte minuto, põe água de novo, então isso é o dia todo". (E1)

"Bom aqui a gente procura né, na parte de alimentação, faze tudo que ele gosta, né, é o dia a dia, a gente ta sempre junto, o que pode fazê nóis ta sempre ao lado fazendo". (E2) 
"A gente faz o acompanhamento, né, a cumida tudo certim nos horário, a verdura que ele gosta, é fruta, tudo certim, tudo no horário certo". (E5)

De acordo com as alterações nutricionais podem se apresentar no início do diagnóstico do câncer, sendo comum a desnutrição, variando conforme a localização e o tipo de neoplasia maligna. O mais importante é instituir uma terapia nutricional com o objetivo de prevenir e/ ou corrigí-la ${ }^{15}$.

Os participantes relatam também a importância dos cuidados com a higiene pessoal e das roupas:

"Uai eu cuido muito bem, trato ele bem, eu faço as coisa pra ele, eu faço cumidinha pra ele, lavo roupa, se ele esquece de tomá os remédios eu falo que ele ta esquecendo, pra ele tomá". (E6)

"[...] tem um rapaz que da o banho nele duas vezes por semana, e os outros dias eu dou de pano na cama". (E9)

A higiene faz com que a pessoa sob cuidados paliativos assegure sua dignidade e conforto físico por causa da dependência parcial ou integral que ele desenvolve em decorrência da doença².

Segundo os cuidadores entrevistados, além dos cuidados com a alimentação e higiene, eles auxiliam também acompanhando o idoso ao médico, com a medicação e ficando atento nos casos de dor:

"Ele toma morfina direto, ele fala, ele fica quetim, ele não responde nada que você pergunta, se começa a doe a barriga, ai ele grita, lá da cozinha escuta, o ombro dói muito de ficá de lado, ai ele fala, mais do contrário ele não fala nada". (E1)

"Tem dia que ele reclama de dor, mas graças a Deus, depois de tudo que ele já passou, hoje em dia ele ta bem melhor. A gente leva no médico quando precisa às vezes tem o remédio também que ele toma, pra tirar a dor, ele faz bastante repouso" (E5)

É direito do indivíduo o alívio da dor e dos demais sintomas e, cabe aos profissionais criar meios para a diminuição do sofrimento provocado pela dor e pela doença ${ }^{16}$.

\section{Dificuldades sentidas pelo cuidador}

Estes relataram que muitas vezes são deixados de lado, pois na maioria das vezes, o foco do profissional da saúde é a pessoa doente somente, sendo também importante que os profissionais se atentem para esses cuidadores, pois precisam de auxílio e apoio em relação aos cuidados oferecidos, já que podem desenvolver sobrecarga física, psíquica e social ${ }^{17,18}$.

De acordo com os cuidadores entrevistados as dificuldades encontradas para realização dos cuidados encontramse relacionadas às próprias limitações devido à idade, além das limitações físicas:

"[...] o dia-dia não é fácil não. Minha cozinha é lá fora e eu operei das varizes, eu desço e subo. Minha fia minhas perna dói tanto quando eu saio correndo, porque tudo tem horário né, olha cuidá de doente não é fácil. Eu acho que o mais difícil seria o banho né, mais graças a Deus eu to conseguindo. O moço da o banho, conseguindo paga né, é claro, então enquanto eu pude, aí se precisá eu tento virá ele à noite, não é fácil não, porque ele não consegue, ele mexe mesmo só o braço de cá, o resto não mexe nada". (E1)

"Então fácil não é porque eu cuidá de mim com 71 anos e dele com 77 não é fácil né, muito difícil pra mim, mais o que eu posso faze eu faço." (E7)

Outra dificuldade encontrada nos relatos, diz respeito ao abandono das atividades laborais para se dedicar ao familiar adoecido: 
"Então o pobrema é esse ai né, igual que eu to te falando, eu cuido dele é meio compricado, porque pro se vê eu tenho que pará, eu parei tudo pa larga tudo meu serviço pa cuida dele, pa andá pa Passos, porque a gente tem que anda né, é compricado". (E3)

Foi observado também o medo do familiar de realizar aadministração de medicamentos, ou seja, medo da responsabilidade de medicar, ficando esta ao encargo do próprio idoso:

"Eu mando ele toma o remédio que ele sabe, eu não do porque eu fico com medo, ele senti mais essa dor da cabeça, mais ele já tem o medicamento, quando ele senti ele toma." (E6)

No tema "Suporte para realização do cuidado" é abordada a importância de se prestar um cuidado integral ao paciente oncológico, com uma equipe interdisciplinar, devido à complexidade do problema, à grande demanda de cuidados e instabilidade do quadro clínico da pessoa com câncer ${ }^{19}$. Nesse contexto, o profissional enfermeiro tem grande destaque, já que permanece com mais constância ao lado dos doentes e familiares. O familiar, também é valorizado no processo do cuidado e contribui para o conforto físico e psicológico da pessoa com câncer.

De acordo com os cuidadores participantes do estudo, estes recebem suporte dos profissionais da Associação de Combate ao Câncer (ACCa) como enfermeiros, psicólogo, assistente social e nutricionista, além do apoio de familiares, amigos, equipe das Unidades de Saúde da Família e do Hospital do Câncer da região.

"Eu tive apoio do doutor do postim do meu setor USF e também o pessoal do hospital de Passos, que a gente foi muito bem acolhido lá...as infermeiras do postim, no hospital eu tive muito apoio dos médicos e da equipe de enfermagem...minha família né, filhos que são muito atenciosos com ele. Tive muito suporte mesmo com os familiar...vem muita visita, sempre tem gente aqui, de domingo a segunda". (E2)

"Recebe visita sim do pessoal da ACCa, assistente social e nutricionista e ocêis que ta aqui...eu vo lá na ACCa que eles me deu o remédio dele..." (E3)

Cura

Foi abordado, através de relatos em que o idoso com câncer em cuidados paliativos usa a religiosidade como estratégia de enfrentamento do sofrimento e angústia provocados pela doença e até mesmo em busca da cura. Quando o doente utiliza a força da mente aliado a fé religiosa, com a intenção de recuperar o agravo, pode se sentir melhor e com maior disposição para enfrentar os desafios, melhorando o seu quadro clínico ${ }^{20}$. Os cuidadores entrevistados acreditam na cura do familiar, especialmente pela fé em Deus:

"Só Deus né fia, ta nas mãos de Deus, o médico lá de Passos já termino o tratamento, intão agora é só Deus..." (E1)

"Uai eu credito assim né porque essa doença não tem cura mais eu tenho muita fé em Deus, eu tenho fé em Deus". (E3)

A "morte" também foi abordada e a maioria dos cuidadores entrevistados relatou evitar o assunto sobre a morte com o idoso. Alguns acreditam na vida após a morte e conversam sobre ela somente com outros familiares, ou ainda guardam o tema para si. Apesar das múltiplas oportunidades de experimentar a vulnerabilidade da vida diante de várias situações, há grande dificuldade de aceitar a questão da morte e do morrer ${ }^{21,22}$.

"Não, a gente não fala, porque cada um guarda pra si, porque a gente não que fica falando perto dele tal, a gente fala mesmo assim da vida sabe, incentivando a vontade de vive que ele tem." (E5)

"A morte pra nóis ela não existe, é só uma mudança de vida." "A gente até nem pensa muito na morte, a gente pensa mais na vida, porque a vida continua após a morte." (E2)

"Não eu não converso isso com ele não." (E3) 
Apenas um cuidador relatou conversar com o idoso sobre a morte, encorajando-o para sua aceitação:

"[...] fala, nóis encara natural, eu sou realista, eu falei pra ele, eu não me apego com nada, a gente tem que faze o bem aqui, e pensa que um dia agente vai, ninguém vai fica, a morte é real, não tem que fica com medo dela, eu falo memo, eu falo pra ele, se um dia acê fo primeiro, vai em paz no sossego, se eu fo é a mesma coisa. Não tem nada que ficá agarrado nas coisa aqui não, às vezes ele fala assim, tenho medo de eu morre você fica suzinha e os outro judiá doce. Falei não, quem manda nimim sou eu, enquanto eu tivé lúcida coisan, o eu que tomo conta de mim, nóis conversa nisso aí sim, eu sou realista, não tenho medo de morte, ta doente vai morrê, de todo jeito nóis vai morrê." (E9)

Na categoria "Ações para a promoção do bem-estar", é abordado que o bem-estar da pessoa varia, desde a ausência de dores, queixas, sofrimentos somáticos ou psíquicos até o prejuízo do desempenho pessoal ou social. A promoção do bem-estar também pode significar a satisfação das necessidades conscientes ou inconscientes, naturais ou psicossociais desses idosos. Por ter um conceito ampliado, talvez seja difícil explicar ao paciente o seu significado, devido à sua subjetividade. Assim, o bem-estar depende de cada pessoa ${ }^{7}$.

De acordo com os cuidadores entrevistados, as conversas e os passeios são estratégias utilizadas para proporcionar bem-estar ao paciente, conforme pode ser observado nas seguintes falas:

"Eu faço tudo que eu posso, tudo pra ele agrado ele, converso com ele mais ele não interessa por nada, ele não qué toma conhecimento de nada. " (E1)

"A gente procura saí bastante sabe, faze tudo certim, o que tem faze com ele nas horas certa, a gente procura passea com ele, pra ele se distraí, assim ele gosta sabe". (E5)

"Fica só eu e ele bem dize, porque meu marido trabalha e conversa, nóis conversa ele conta os causo dos antepassado dele, da família, então nóis conversa muito. Ele vai muito passeá, ele sai na bicicletinha dele". (E6)

A análise dos temas revelou a importância de ser cuidador, principalmente de um familiar idoso com câncer e em cuidados paliativos. Também demonstrou o quanto eles valorizam o cuidado, o zelo e o carinho por esse familiar, apesar de conviver constantemente com o peso da responsabilidade e da sobrecarga que os cuidados oferecidos trazem aos pacientes e aos familiares.

\section{Considerações Finais}

Os cuidadores familiares de idosos em tratamento oncológico, apesar de não terem conhecimento sobre o significado de cuidados paliativos, os praticam em dimensões variadas, dependendo da realidade de cada um. Alguns desses cuidados estão relacionados à alimentação saudável, higiene adequada e alívio da dor, já que eles relatam estar atentos à medicação prescrita. Entretanto, alguns referem que se sentem desamparados e sobrecarregados ao oferecer os cuidados necessários ao familiar com câncer, além de enfrentar limitações físicas e lou decorrentes da idade mais avançada. Neste sentido, observa-se a falta de um profissional da saúde para dar o suporte familiar necessário, o que pode ocorrer se a maioria dos profissionais da área não tiver conhecimento adequado para oferecer cuidados paliativos, os quais devem estar voltados aos pacientes e também aos seus familiares, no caso da presente pesquisa, ao cuidador familiar.

A pesquisa demonstrou também que 0 ato de cuidar de um familiar traz consigo um peso/valor muito grande, devido à existência de uma relação sentimental aliada ao medo e à angústia gerada pela progressão da doença e à incerteza da morte, o que traz desconforto emocional, o qual deveria ser amenizado com apoio psicológico por parte da equipe de saúde. Ainda assim, todos sempre relatam muita fé e esperança pela cura do familiar, o que demonstra a valorização da espiritualidade para o enfrentamento da doença, um dos fatores indispensáveis para oferecer cuidados paliativos.

Apesar de receberem a atenção das unidades de saúde da família, a ACCa e sua equipe multidisciplinar como referência de apoio ao idoso em tratamento oncológico teve sua relevância comentada por todos os cuidadores.

Portanto, torna-se de extrema importância a capacitação do enfermeiro e da equipe de saúde da família para oferecer cuidados paliativos adequados ao idoso com câncer no domicílio, já que esse papel tem sido desenvolvido pela ACCa que se destacou nesse contexto, para que os serviços sejam complementados entre si. 
Assim, o enfermeiro por ter maior proximidade ao paciente oncológico, deve desenvolver estratégias de educação e capacitação dos demais profissionais, além de oferecer orientação adequada paral auxiliar os cuidadores familiares a aprimorar o cuidado oferecido, de forma que eles se tornem mais seguros e tranquilos nas suas atribuições do dia a dia.

\section{Referências}

1. Ministério da Saúde (BR). Instituto Nacional de Câncer José Alencar Gomes da Silva. Estimativa 2016/2017: incidência de câncer no Brasil. 2015. Disponível em: <http://www.inca.gov.br/wcm/dncc/2015/index.asp>. Acesso em: 02 jan. 2016. 2. ANCP - Academia Nacional de Cuidados Paliativos. Manual de Cuidados paliativos. 2009. Rio de janeiro: p. 338.

3. Ministério da Saúde (BR). Bases do tratamento do câncer. Disponível em: <http://bvsms.saude.gov.br/bvs/publicacoes/ inca/acoes_cap6.pdf> Acesso em: 30 de setembro de 2015.

4. Kovács, M. Educação para a morte: temas e reflexões. São Paulo: casa do psicólogo, 2003 a. In: Santo, F. Cuidados Paliativos: discutindo a vida, a morte e o morrer. São Paulo: Atheneu, p. 46, 2009.

5.Campolina AG, Adami F, Santos JLF, Lebrão ML. A transição de saúde e as mudanças na expectativa de vida saudável da população de doenças crônicas. Caderno de saúde pública. 2013;29 (6): 1217- 1229.

6. Soares LC, Santana MG, Muniz RM. O fenômeno do câncer na vida de idoso. Cienc cuid saúde. 2010 out/dez; 9 (4): 660-667.

7. Monteiro DR, Kruse MHL, Almeida MA. Avaliação do instrumento Edmonton Symptom Assessment System em cuidados paliativos. $2010 \mathrm{dez} ; 31$ (4): 785-793.

8. Lenza NFB. Primeiro ano de pós-operatório: significado para a pessoa com estoma intestinal por câncer colorretal. Tese (Doutorado). Escola de Enfermagem de Ribeirão Preto (USP). 2016; f. 201.

9. Rocha LS, Beuter M, Neves ET, Leite MT, Brondani CM, Perlini NMOG. O cuidado de si de idosos que convivem com câncer em tratamento ambulatorial. 2014 jan/mar; 23 (1): 29-37.

10. Fratezi FR, Gutierrez BAO. Cuidador familiar do idoso em cuidados paliativos: o processo de morrer no domicílio. Ciência \& saúde coletiva.2011. 16 (7): 3241-3248.

11. Floriani CA, Schramm FR. Cuidador do idoso com câncer avançado: um ator vulnerado. Caderno de saúde pública. 2006 mar;22 (3): 527-534.

12. Brasil. Conselho Nacional de Saúde. Resoluçãon ${ }^{\circ} 466$, de 12 de dezembro de 2012. Aprova normas regulamentadoras de pesquisas envolvendo seres humanos. Brasília: Diário Oficial da União, 2013.

13. Minayo MCS. O desafio do conhecimento: pesquisa qualitativa em saúde. 12 ed. 2010: p. 412.

14. Bardin L. Análise de conteúdo. 70 ed Lisboa; 1979.

15. Waitzberg DL, Nardi LD, Horie LM. Desnutrição em câncer. 2011 out/nov; 2 (8):62.

16. Silva EP, Sudigursky D. Concepção sobre cuidados paliativos: revisão bibliográfica. 2008; 21 (3): 504-508.

17. Araújo ZS, Araújo CZS, Souto AKBA, Oliveira MS. Cuidador principal de paciente oncológico fora de possibilidade de cura, repercussões deste encargo. Revista brasileira de enfermagem.2009jan/fev; 62 (1): 32-37.

18. Azman S. Quem cuida do cuidador? 2011 out/nov; 2 (8): 62.

19. Silva MM, Moreira MC, Leite JL, Erdmann AL. Análise do cuidado de enfermagem e da participação dos familiares na atenção paliativa oncológica. Texto contexto enfermagem. 2012 jul/set; 21 (3): 658- 666.

20. Teixeira JJV, Lefévre F. Significado da intervenção médica e da fé religiosa para o paciente idoso com câncer. Ciência \& saúde coletiva. 2008; 13(4):1247-1256.

21. Silva RCF, Hortale VA. Cuidados paliativos oncológicos: elementos para o debate de diretrizes nesta área. Caderna de saúde pública. 2006 out; 22 (10): 2055-2066.

22. Borges ADVS, Silva EF, Toniollo PB, Mazer SM, Valelr ERM, Santos MA. Percepção de morte pelo paciente oncológico ao longo do desenvolvimento. Psicologia em estudo. 2006mai/ago; 11 (2): 361-369. 


\section{Denize Alves de Almeida}

Endereço para correspondência - Av. Wenscelau Braz, $n^{\circ} 1018$, Bairro: Lagoinha, CEP: 37950-000, São Sebastião do Paraíso, MG, Brasil.

E-mail: denizealmeida1@gmail.com

Lattes: http://lattes.cnpq.br/6395812449348738

Sandramar de Lima Silveira - sandra.mar.mg@hotmail.com

Wallisete de Almeida Godinho Rosa - walisete@terra.com.br

Mariana Gondim Mariutti Zeferino - marianazeferino@libertas.edu.br

Nariman de Felicio Bortucan Lenza - narimanlenza@gmail.com

\section{Enviado em 04 de fevereiro de 2017.} Aceito em 05 de junho de 2017. 